\title{
Orlanda Amarílis, Vera Duarte e Dina Salústio: a tessitura da escrita de autoria feminina na ficção cabo-verdiana
}

\author{
Lílian Paula Serra e Deus*
}

\begin{abstract}
A formação da literatura cabo-verdiana vai ao encontro da construção de uma busca pela ideia de caboverdianidade pautada na valorização da cultura e das tradições do arquipélago. O período historicamente conhecido como Claridade, iniciado na década de 1936, em Cabo Verde, contribuiu significativamente para o fortalecimento de uma literatura de feições cabo-verdianas. Claridade teve como idealizadores João Lopes, Baltasar Lopes, Jorge Barbosa e Manuel Lopes e propunha, a partir de uma releitura de movimentos externos (modernismo brasileiro, neorrealismo português, etc.) e internos, uma estética pautada no culto ao chão crioulo.

Claridade reforça a tomada de consciência sobre a realidade cabo-verdiana, já assumida de maneira esparsa por artistas "pré-claridosos" como Eugênio Tavares, Pedro Cardoso e o próprio Jorge Barbosa, com a publicação de "Arquipélago", em 1935. Claridade expõe, pelos caminhos da arte, sobretudo da literatura, para além dos aspectos naturais que constituem o arquipélago, as cruezas do cotidiano ao qual o cabo-verdiano estava submetido. Como pontua Nazareth Fonseca e Terezinha Moreira:
\end{abstract}

\begin{abstract}
As linhas mestras dos movimentos dos "claridosos" estão praticamente condensadas na obra de Jorge Barbosa. A preocupação fundamental da sua poesia é revelar as situações com que diariamente se defronta o caboverdiano: a fome, a miséria, a falta de esperança no dia de amanhã, a seca e os seus efeitos devastadores. Os grandes tópicos são o lugar, o ambiente socioeconômico e o povo; e todos em relação constante com o mar, elemento gerador de outros dois temas tratados na poética de Jorge Barbosa: a viagem e o sonho de encontrar uma terra prometida (FonsECA e MOREIRA, 2007, p. 19).
\end{abstract}

Nos anos de 1936 e 1937 são publicados os primeiros números da Revista Claridade, criada na Ilha de São Vicente, importante suporte para a divulgação dos textos dos claridosos. A Revista Claridade constituiu-se de, ao todo, nove números,

Professora Adjunta na Universidade da Integração Internacional da Lusofonia Afro-brasileira (UNILAB), Brasil. E-mail: lilianedeus@gmail.com . 
sendo os seis últimos publicados no período entre 1947 a 196o, e tornou-se o símbolo da ruptura com uma literatura distanciada da terra e do povo cabo-verdiano, embora já tivesse havido uma sinalização nessa direção evidenciada por artistas do período pré-claridoso, como mencionado anteriormente.

Não obstante sua importante contribuição para o cenário artístico, cultural e político cabo-verdiano, a Revista Claridade não traz o nome de mulheres em suas publicações, o que evidencia a formação, sobretudo, de uma literatura moderna muito calcada em vozes masculinas. Nesse sentido, Claridade reforça o patriarcalismo cabo-verdiano cujos pilares não se ancoram somente no colonialismo, mas estão também fincados nos assentos das tradições do arquipélago.

Na esteira da Revista Claridade, surgem a Revista Certeza (1944) e o Suplemento Cultural (1958). A Revista Certeza surge a partir de um distanciamento ideológico entre alguns autores de Claridade. Fazem parte da publicação nomes como Corsino Fortes que, durante alguns anos, contribuiu e participou ativamente de $\mathrm{Cla}$ ridade. A Geração de Certeza promove uma inflexão ao romper com o que chamavam de visão pasargadista, segundo eles, adotada pelos claridosos, a partir de um determinado momento de Claridade.

O termo pasargadista, cunhado pela Geração de Certeza e atribuído aos escritores de um determinado período de Claridade, surge como crítica ao suposto evasionismo encenado nos textos dos claridosos, que se acentua a partir do diálogo estabelecido entre os claridosos e a poética de Manuel Bandeira, principalmente os intertextos entre o poema de Manuel Bandeira Pasárgada e a escrita de Jorge Barbosa. Escritores da Geração de Certeza como Ovídio Martins e Onésimo Silveira tecem críticas contundentes ao suposto cariz pasargadista dos autores de Claridade.

Manuel Ferreira (1986) sublinha que o cariz pasargadista do qual os Claridosos são acusados não seria, efetivamente, um desejo de sair da terra natal, em busca de um lugar ideal, mas um desejo de vencer as dificuldades advindas de algumas condições inóspitas do contexto geográfico cabo-verdiano, embora os escritores da Geração de Certeza não corroborem essa perspectiva.

A Geração de Certeza propõe também um olhar para a terra que enalteça suas raízes crioulas. Como acentuam Fonseca e Moreira (2007) a respeito da obra de Corsino Fortes, integrante da Geração Certeza, que, como mencionado anteriormente, desvinculou-se, por razões ideológicas, da Revista Claridade:

A problemática da identidade cabo-verdiana está presente na obra de Corsino Forte. Porém, ao contrário dos "claridosos", a nova poesia é uma expressão artística cuja formulação sugere e reflete a dinâmica do real e nela intervém (Fonseca e Moreira, 2007, p. 21).

Nesse sentido, os escritores da Geração de Certeza propõem fincar os pés na terra e assumem um compromisso com a ação e a mudança, a partir, sobretudo, 
de textos literários que privilegiem a reconstrução da identidade cabo-verdiana e o combate à opressão.

É nesse contexto da Geração de Certeza que surge um dos nomes mais significativos desse período: Orlanda Amarílis, "assumindo as variantes de um mesmo tema - o do exílio, da diáspora, da solidão -, mas também observando, com olhos muito ternos, o dia a dia das mulheres e das ilhas" (Fonseca e Moreira, 2007, p. 22). Ressalte-se a importância de Amarílis em um momento de formação da moderna literatura cabo-verdiana em que a autoria feminina era quase nula no que diz respeito às publicações. Para além disso, a temática abarcada pela autora privilegia não somente o olhar para a terra, mas sobretudo o olhar para as mulheres dessa terra. Faz-se importante ressaltar que, ainda hoje, o enfrentamento e a resistência ao silenciamento imposto pela sociedade cabo-verdiana às mulheres se faz evidente pelo número esvaziado de mulheres que figuram, por exemplo, nas antologias cabo-verdianas. Nesse sentido, Orlanda Amarílis, Dina Salústio e Vera Duarte são nomes que rasuram a constituição de um sistema literário homogêneo, centrado em autores homens.

A moderna literatura cabo-verdiana urdida a partir do Movimento Claridade, como enfatizado anteriormente, nasce da busca por uma identificação com a terra; pautando-se no engendramento de uma ideia de caboverdianidade e revela nomes como Baltasar Lopes, Manuel Lopes, Jorge Barbosa, João Lopes, mas, reitera-se, não abarca em sua constituição escritas de autoria feminina. É, portanto, um movimento significativo no que tange a constituição do sistema literário cabo-verdiano moderno, mas não traz na sua tessitura as "vozes-mulheres" (apropriando-me do termo de Conceição Evaristo) que constituem essa sociedade, o que, de certa maneira, é sintomático.

Pautando-se na premissa de que a literatura, sobretudo desse período, apropriase de questões pungentes da realidade social cabo-verdiana, sustentando-se, desde o início, no diálogo tecido com o neorrealismo português, é fundamental se pensar que a moderna literatura cabo-verdiana reflete na sua formação os traços de uma sociedade patriarcal, pois embora os Claridosos tenham exposto e denunciado, pelos caminhos da arte e da ficção, a fome, a miséria, a seca, as difíceis condições climáticas, a relação com o mar, a questão do exílio, da diáspora, da solidão, entre outras temáticas, essa inserção crítica na realidade exclui do diálogo literatura/realismos/sociedade a figura da mulher. A primeira antologia de poesia caboverdiana organizada por Jaime Figueiredo, Modernos poetas cabo-verdianos (1961) expõe essa exclusão. Ela é composta por 80 poemas de autoria de 20 poetas, todos eles homens, o que ratifica a ideia de uma literatura hegemônica masculina.

Amarílis impõe-se a esse silenciamento somando ao olhar para a terra que enalteça suas raízes crioulas, uma ideia de construção da identidade da terra vinculada à identidade da mulher cabo-verdiana. Amarílis faz, dessa maneira, emergir do silenciamento questões pautadas, sobretudo, pela experiência de ser mulher em sociedades estruturadas pelo patriarcalismo. A questão da diáspora, das migrações, 
é trazida, sobretudo, pela ótica das mulheres que passam a ser sujeito/protagonista da própria história. Como acentua Grada Kilomba: "escrever emerge como um ato político [...] enquanto eu escrevo eu me torno a narradora e a escritora da minha própria realidade, a autora e a autoridade na minha própria história" (KilomBA, 2019, p. 28). Dessa maneira, Amarílis não somente dá visibilidade às dificuldades as quais as mulheres têm que cotidianamente enfrentar em sociedades patriarcais, mas promove uma intenção de rasura de um ideal colonialista, que se ancora, sobremaneira, na ideia de subalternização da figura feminina.

\section{Orlanda Amarílis}

Orlanda Amarílis nasceu em 1924, em Assomada, Santa Catarina, Cabo Verde. Na cidade de Mindelo, Amarílis completa os seus estudos primários e, também na Ilha de São Vicente, inicia os estudos secundários no Liceu Gil Eanes. Mudou-se para Goa, e viveu na capital Panguim, durante seis anos, onde conclui os estudos. Anos depois, a escritora frequentou o Curso de Ciências Pedagógicas na Faculdade de Letras de Lisboa.

Amarílis publicou Cais do Sodré té Salamansa, em 1974, Ilhéu dos pássaros em 1983 e A casa dos mastros, em 1989, obras que privilegiam a narrativa curta. Em seus contos, Amarílis explora questões importantes relativas à cultura caboverdiana, direcionando o olhar, especialmente, para o cotidiano das mulheres do arquipélago.

Como acentua Benjamin Abdalla Júnior:

Voltando ao contexto criado a partir de Manuel Bandeira, podemos afirmar que o olhar de Orlanda Amarílis vai igualmente na direção inversa à do poeta brasileiro. Mais: ela não aceita a perspectiva patriarcal das libertinagens de Bandeira, que reduziam o amor a atos sexuais com prostitutas; sua bandeira é outra, de caráter feminista (ABDALla JúNIOR, 2003, p. 288).

Maria Aparecida Santilli corrobora a perspectiva de Abdalla Júnior e evidencia através do texto "As mulheres-sós de Amarílis" (1985) a ótica abarcada por Amarílis em Ilhéu dos pássaros (1983):

Ilhéu dos Pássaros é um livro de estórias de mulheres caboverdianas, mulheres sós. Aparas sociais, elas giram no espaço de suas Ilhas, recortadas dos homens- pais, maridos ou parceiros cuja ausência (ou eventual presença) é, no entanto, o eixo em torno de que se descreve a órbita de suas vidas. Figuras literárias femininas, paridas de outra mulher, a escritora Orlanda Amarílis, ganham presença no mundo com o alto custo da representação de ser mulher no universo de Cabo Verde (SANTILLI, 1985, p. 107).

A metáfora das ilhas que circunscreve os contos de Ilhéu dos pássaros (1983) enfatiza a solidão das mulheres cabo-verdianas, as "mulheres-sós" apontadas por 
Santilli (1985), que embora objetificadas e marginalizadas, resistem para se fazerem existir em um contexto no qual persistem as estruturas sexistas.

O conto "Thonon-les-ban", que abre a obra Ilhéu dos pássaros (1983), é construído em torno da personagem Nh'a Ana, que repisa os conflitos que perpassam o cotidiano de muitas mulheres cabo-verdianas. A personagem central, Nh'a Ana, viúva e mãe de Piedade, Maria Antonieta, Juquinha e Chiquinho, vive o dilema da dor de estar distante de uma das filhas, levada a Thonon-les-Bains, França, pelo enteado Gabriel, a seu pedido. A separação de sua filha Piedade, causada pela emigração, é uma realidade muito presente na vida dos cabo-verdianos, resultante, principalmente, de condições climáticas desfavoráveis. Amarílis vale-se de estratégias textuais que encenam a crueza dessa realidade cabo-verdiana ao construir personagens para as quais toda a projeção de futuro está na ideia de exílio, como evidenciado pela conversa estabelecida entre as personagens Nh'a Ana e sua comadre:

Mas comadre Ana, bocê não tem medo de mandar a sua filha assim sozinha para tão longe?

Como comadre, medo de quê? Medo de nada. Gabriel explicou tudo muito bem explicado. Piedade vai agora, depois, daqui a uns dois anos vai o Juquinha, depois Maria Antonieta e depois vou eu mais o Chiquinho.

Ah, comadre Ana, Deus há-de acompanhar vocês todos (AMARílis, 1983, p. 13).

As conversas com a comadre e as notícias da filha distante que chegavam através de cartas preenchiam os dias de Nh'a Ana e a faziam crer em uma possibilidade de futuro melhor para si e para os filhos:

Sabe comadre, se nh'a filha me mandar algum dinheirinho, posso começar um negócio de comidas [...]

Em sonhos enrodilhada, na esperança de abrir o seu botequim, nh'a Ana ia desfiando os dias e recebendo notícias da filha (AmARílIs, 1983, p. 14-15).

Embora a emigração seja vista com encantamento pelos personagens do conto, Amarílis evidencia a dureza do processo migratório, principalmente para as mulheres, a partir da violência sofrida pela filha, tratada como um objeto ou como um bicho, "degolada como se de um porco se tratasse" (Amarílis, 1983, p. 24). Como acentuado, o conto que abre a obra Ilhéu dos pássaros (1983) traz já no seu título uma relação diaspórica: Thonon-les-ban é o nome de uma cidade francesa para a qual uma das personagens da narrativa, Piedade, migra em busca de melhores condições de vida. Em "Thonon-les-ban", as personagens femininas são vítimas não somente da xenofobia advinda do processo migratório, mas também da violência de gênero, que é acentuada pelo desfecho do conto, o feminicídio. Nesse sentido, a ideia de que as mulheres são acometidas por violências múltiplas é trazida à cena. 
A violência contra Piedade foi engendrada pelos ciúmes do seu parceiro francês, que via a mulher como objeto de posse, mas a culpabilização pelo crime foi direcionada aos estrangeiros, o que corrobora a perspectiva negativa abarcada pela emigração no conto:

Mas porquê Gabriel, porquê não disseste na polícia que aquele home é que tinha esfaqueado a falecida? Mas porquê?", perguntava nh'a Ana entre soluços.

Gabriel teve dificuldade em explicar-lhe. Isso não adiantava nada. Eles sabiam mãe Ana, sabiam, isto é, desconfiavam, mas eu sou emigrante. Emigrante é lixo, mãe Ana, emigrante não é mais nada (AMARílIs, 1983, p. 25).

No conto, através da simbologia do jogo de cartas, há uma sinalização para o desfecho da história, como se, por meio dessa estratégia textual, a autora trouxesse a denúncia de que a violência de gênero extrapola as fronteiras cabo-verdianas e se estende a outros espaços. As estruturas sociais machistas estabelecem uma espécie de destino a ser vivenciado pela mulher, que a literatura de Amarílis, ao denunciar, promove uma ruptura a partir da contestação da lógica sexista. Para além disso, o conto traz a questão da solidão da mulher cabo-verdiana muito presente na obra da autora. Nh'a Ana é uma das "mulheres-sós" de Orlanda Amarílis, das quais nos fala Maria Aparecida Santilli. A personagem Nh'Ana configura-se na mulher-só que espera por notícias da filha exilada. Segundo pontuam Fonseca e Moreira, a filha Piedade também pode ser percebida em sua solidão:

Piedade é outra mulher-só cuja existência gira em torno de dois homens: o meio irmão Gabriel e o namorado francês Jean. Exilada do espaço de referência tradicional de nh'a Ana, Piedade é chamada ao mercado de trabalho da sociedade francesa moderna. Porém não consegue exilar-se de uma outra tradição: a da representação machista do homem que não lhe faculta a independência emocional e a expressão de sua individualidade. Seja na relação com Gabriel ou com Jean, pesa sobre Piedade a ideologia da intervenção do homem protetor, que lhe delimita as ações (FonseCA e MOREIRA, 2007, p. 25).

No conto "Cais do Sodré, pertencente à coletânea Cais-do-Sodré té Salamansa (1991), a perspectiva da mulher também é contemplada, a partir da encenação de questões significativas no contexto cabo-verdiano, através da construção de personagens mulheres e dos conflitos que as envolve. Segundo Abdalla Júnior (2003, p. 289): "Esse conto serve de pórtico para essa coletânea e permite identificar estratégias narrativas e motivos temáticos que têm recorrência no conjunto das produções de Orlanda Amarílis". No conto "Cais do Sodré", o universo das oralidades é repisado a partir de uma narrativa tecida em conversações que se estruturam 
pelas vozes de mulheres. Portanto, o universo das oralidades é atualizado no âmbito do texto escrito, sobretudo, a partir de encenações centradas na figura da mulher. Em "Cais do Sodré", o trânsito diaspórico é evidenciado através da personagem Andresa, que traz o conflito de Cabo Verde/Portugal e, por meio da memória, busca refazer os laços com a terra e suas raízes crioulas:

Andresa rebusca na memória a família da cara parada na sua frente. Parece daquela gente de nhô Teofe, um de S. Nicolau a quem os estudantes tinham alcunhado de Benjamin Franklin. Ou será parente de nhô Antônio Pitra, irmão do Faia, há muito embarcado para a Argentina? (AmARílis, 1991, p. 11).

Dessa maneira, as conversas no Cais, iniciadas por Andresa, com certa parcela de contragosto, por não conseguir controlar a sua vontade, a reconfiguram, de certa maneira, ao espaço cabo-verdiano e reforçam a cultura da contação de histórias, das memórias veiculadas pelas oralidades e pelas línguas crioulas: "Andresa relembra tudo isto com tanta minúcia como se nunca se tivesse desapegado da mãe terra [...]" (AMARÍlIs, 1991,p. 18).

Abdalla Júnior assevera que "as conversas costuram as narrativas que se iniciam no Cais-do-Sodré e se dirigem aos subúrbios, uma linha vetorial que chega a Cabo Verde" (ABDAlla JúNIOR, 2003, p. 297). Ainda, segundo Abdalla, dessa forma, no conto Cais-do-Sodré, a figura do griot africano é trazida, especialmente, através da personagem Bia Antonia:

A imagem de Bia Antonia com o fumo no canto da boca é correlata a dos gritos suburbanos do continente africano. Há, pois, comutação de papéis, como também veio a ocorrer no continente. Símbolos de identidade, essas contadoras de história preservam a memória da terra-sempre uma terramãe. Essa simbolização feminina leva-nos a situá-la como uma Mátria (no dizer de uma feminista, Natália Correia), em oposição à Pátria (de caráter patriarcal, masculina), identificada com o poder colonial (ABDALLA JÚNIOR, 2003, p. 298).

Andresa reforça identidades femininas que se entrecruzam, se fortalecem no e pelo diálogo e que encontram conforto na figura da terra-mãe.

Amarílis inscreve seu nome na literatura cabo-verdiana, desde sua formação, através de movimentos literários importantes como o movimento encabeçado pela Geração de Certeza, da qual fez parte, na década de 1940.

A obra de Amarílis, como acentuado, problematiza questões importantes do cenário sociocultural cabo-verdiano como, por exemplo, a ressignificação da identidade cultural, a violência de gênero, a opressão sofrida pelas mulheres, a solidão, a emigração. 
A temática apontada nas obras de Amarílis se faz recorrente, como uma espécie de discurso que é necessário ser enfatizado pelo viés da repetição. A própria lógica da construção de personagens femininas no centro de suas narrativas aciona uma ótica feminina e feminista que intenta rasurar padrões patriarcais e instaura o olhar para o mundo a partir de olhares femininos. As construções e estratégias discursivas de Amarílis prezam sempre pelas vivências de mulheres, até então invisibilizadas, não somente pelo tecido cultural cabo-verdiano, mas também na grande maioria das construções literárias, o que torna a sua escrita bastante significativa, não somente para a literatura Cabo verdiana, mas, especialmente, para a literatura-mundo.

$\mathrm{Na}$ esteira de Amarílis surgem nomes significativos como os de Dina Salústio e Vera Duarte, escritoras que tecem suas literaturas calcadas no protagonismo da mulher, que é trazida das margens para o centro das narrativas. A denúncia de realidades desiguais e opressoras ratificadas, especialmente, pela desigualdade de gêneros, é encenada nas obras de Duarte e Salústio.

Dina Salústio e Vera Duarte, com uma estilística peculiar e bastante significativa, ao repisar temáticas encenadas por Amarílis, dialogam com a autora e se impõem em meio a um contexto literário predominantemente masculino.

\section{Dina Salústio}

Bernardina de Oliveira Salústio nasceu em 1941, em Santo Antão, Cabo Verde. Foi fundadora da Associação dos Escritores Cabo-verdianos.

A autora tem sua estreia na literatura cabo-verdiana em 1994, a partir da publicação da obra de contos Mornas eram as noites. Ainda em 1994, publica o livro de contos infanto-juvenil A estrelinha Tlim Tlim. Em 2002, a obra infanto-juvenil Que os olhos não veem, escrita em parceria com a Marilene Pereira, é publicada. É autora da antologia de poetas cabo-verdianos de 1998 e da antologia de poesia africana de língua portuguesa do século XX, de 1999. O livro A louca de Serrano, cuja primeira edição é de 1998, inaugura o romance cabo-verdiano de autoria feminina. Posteriormente, em 2009, Salústio publica o romance Filhas do vento e, em 2018, o livro de contos Filhos de Deus. Veromar, romance publicado pela editora Rosa Porcelana, em 2019, é a sua obra mais recente. A autora é também uma das fundadoras da Academia Cabo-verdiana.

A literatura de Salústio, portanto, vai ao encontro da ideia de valorização da identidade cabo-verdiana, circunstanciada pelas marcas regionais (oralidades, mornas/Mornas eram as noites) e da ficionalização que não escamoteia a dura realidade que se inscreve no cotidiano dos cabo-verdianos, evidenciando-se, nesse contexto, as experiências sociais das mulheres. Dina Salústio é responsável, inclusive, como mencionado acima, pelo primeiro romance de autoria feminina cabo-verdiano: A louca de Serrano (1988). 
Em entrevista ao site "Ponto Final", Salústio pontua sobre a relação entre a sua escrita e o contexto social que a permeia:

Eu penso que é a realidade que nos leva a escrever. Não é o escritor que vai à procura da realidade, mas a realidade é tão forte que nos obriga a escrever [...] Isso é que me levou a escrever as crônicas e as publicar. Era a condição feminina, a condição da criança, os maus-tratos, os abusos. Depois era a vontade de sermos ouvidas, sermos vistas, nós mulheres (SALÚSTIO, 2018).

A autora sublinha, pois, que a vontade de se fazer ouvir é o que impulsiona a sua escrita. A sua situação feminina, muitas vezes silenciada em um contexto social falocêntrico, é o gatilho para concepção de uma escrita literária que confronte esse silenciamento. Dessa maneira, o enfrentamento da opressão feminina, dentro de uma estrutura patriarcal, atravessa toda a obra de Salústio.

Em Mornas eram as noites (1994), por exemplo, a autora vale-se de estratégias discursivas e construção de personagens que ratificam o seu olhar atento à situação da mulher no espaço cabo-verdiano. Desde o título da obra, a alusão à caboverdianidade é trazida. Como enfatiza Simone Caputo Gomes:

O título de sua coletânea de contos reitera a associação da prosa com o poético ao dar relevo à morna, modalidade musical típica de Cabo Verde, que veicula a poesia oral. Tradicionalmente canto de mulher, o entendimento do lugar cultural da morna no mundo cabo-verdiano pode derramar outras luzes sobre o título: "música eram as noites" é uma leitura para Mornas eram as noites. Música de mulheres em que a mulher é a peça principal. Para além, música de nacionalidade e identidade. Como preâmbulo à coletânea a autora assinala: "de como elas se entregam aos dias" (GoMEs, 2008, p. 219).

Nesse sentido, se, como afirmado anteriormente, Salústio compromete-se a romper o silenciamento das "vozes-mulheres" cabo-verdianas, essa prerrogativa já está evidenciada no título, que abarca as vozes de um feminino enaltecido a partir, primeiramente, da entoação de cantos - as mornas - que reivindicam um espaço que é tradicionalmente das mulheres. Ao evocar no título e nos contos o gênero musical tradicional cabo-verdiano, a autora repisa um universo surgido de demandas do feminino e calcado nas oralidades e o reconstrói no espaço do texto escrito.

\section{Vera Duarte}

Assim como Amarílis e Salústio, Vera Duarte traz para a sua escrita o universo surgido de demandas do feminino, acionando uma ótica feminina e feminista que se impõe atravessada pelas questões do imperialismo, sobretudo um sistema literário cujos pilares reproduzem e sustentam esses padrões, questionando-se, assim, as estruturas sociais sexistas. 
Vera Valentina Benrós de Melo Duarte Lobo de Pina, nasceu em Mindelo, Ilha de São Vicente, Cabo Verde. Destacou-se na carreira jurídica como juíza desembargadora, foi Ministra da Educação e presidente da Comissão Nacional para os Direitos Humanos e Cidadania de Cabo Verde. É poeta, ensaísta, cronista, contista e romancista. É autora das obras poéticas Amanhã Amadrugada (1993), Arquipélago da paixão (2001), Preces e súplicas ou cânticos da desesperança (2005), do premiado romance $A$ candidata (2004) e da obra de crônicas, A palavra e os dias (2003), além de uma variada colaboração em jornais, revistas e antologias.

Tanto através da magistratura quanto por meio da produção literária, Duarte revela-se envolta por questões ligadas à mulher e aos direitos humanos. Assim como Salústio, Duarte também traz em suas obras a invocação das muitas facetas do feminino e a preocupação com a condição da mulher na cultura cabo-verdiana.

Em A candidata, por exemplo, Duarte traz como protagonista uma mulher: Marina, que resiste bravamente as opressões, trilhando seu caminho, como sujeito da própria história. Entrecortada por conflitos vários, a trajetória de Marina desemboca em sua candidatura à mais alta magistratura da nação, esvaziando, assim, a perspectiva sexista da existência da mulher como coadjuvante, à sombra de um homem.

Nas palavras de Ana Maria Cabral, responsável pela apresentação da obra:

Quase sempre na literatura, as personagens femininas são retratadas não como sujeitos históricos de resistência contra as opressões, mas como marionetes em um espaço sem história e a sombra do marido. A mulher não passa de uma imagem sofrida da vida ou de um claustro contido de silêncios ou de lamentações.

Marina, aqui, aprendeu desde a adolescência as limitações da ilha e a raridade de meios para sobrevivência do arquipélago [...] Escolhe seu próprio caminho de construção e contribuição para uma nova sociedade, sem taras nem traumas (CABRAL, 2004, p. 5).

Reforçando-se essa perspectiva, ressalta-se o processo de construção da obra a partir do posicionamento da autora, abarcado pela nota ao leitor que abre a narrativa:

Quis escrever uma história em que a mulher fosse o "herói”. Uma história que fixasse para a posteridade o perfil de uma mulher da segunda metade do século XX [...] Cansei-me da imensa beleza das histórias em que as mulheres amam e a única saída é a morte. Quis escrever uma história de mulheres que amam, sofrem, mas... vivem (DUARTE, 2004, p. 11).

A partir da perspectiva da autora, há um deslocamento da mulher à margem das narrativas, quase destituída de humanidade, para o centramento desse sujeitomulher que, a partir da construção de personagens e temáticas que abarcam o uni- 
verso feminino, passa a protagonizar a suas experiências e histórias. A perspectiva da mulher na obra de Duarte, principalmente em A candidata, carrega consigo a pluralidade abarcada pela ideia de identidades que não são fixas e que são, sobretudo, construídas a partir da vontade de mulheres que assumem para si o protagonismo. Como pontua Kilomba:

Escrever é um ato de descolonização no qual quem escreve se opõe a posições coloniais tornando-se a/o escritora/escritor "validada/o e legitimada/o e ao reinventar a si mesma/o, nomeia uma realidade que fora nomeada erroneamente ou sequer fora nomeada (KILOMBA, 2019, p. 28).

Dessa maneira, Duarte sedimenta uma escrita alicerçada nas questões do feminino. As demandas e conflitos do arquipélago são sempre costurados a partir do olhar da mulher; por meio da construção de personagens, estrategicamente pensadas para rasurar uma ótica sexista de mundo e abarcar "vozes-mulheres", muitas vezes silenciadas também pela literatura.

\section{Considerações finais}

Amarílis inscreve seu nome na literatura cabo-verdiana, desde sua formação, através de movimentos políticos-artísticos-literários importantes como o movimento encabeçado pela Geração de Certeza, da qual fez parte, na década de 1940.

A obra de Amarílis, como acentuado, problematiza questões importantes do cenário sociocultural cabo-verdiano como, por exemplo, a ressignificação da identidade cultural, a violência de gênero, a opressão sofrida pelas mulheres, a solidão, a emigração. A temática apontada nas obras de Amarílis se faz recorrente, como uma espécie de discurso que é necessário ser enfatizado pelo viés da repetição. A própria lógica da construção de personagens femininas no centro de suas narrativas aciona uma ótica feminina e feminista que rasura padrões patriarcais e instaura o olhar para o mundo a partir de olhares femininos. As construções e estratégias discursivas de Amarílis prezam sempre pelas vivências de mulheres, até então invisibilizadas não somente pelo tecido cultural cabo-verdiano, mas também na grande maioria das construções literárias, o que torna a sua escrita bastante significativa não somente para a literatura cabo-verdiana, mas, especialmente para a literatura-mundo.

Dina Salústio e Vera Duarte, assim como Amarílis, trazem para os seus textos o universo de histórias que durante muito tempo não foram contadas porque foram silenciadas pela violência de um sistema patriarcal. Nesse sentido, as vozes das "mulheres-sós", termo de Santilli (1985), de Orlanda Amarílis fazem-se acompanhar pelas "vozes-mulheres" encenadas nas obras de Dina Salústio e Vera Duarte, forjando-se, assim, um entretecer de identidades que expõe, denuncia, ressignifica e reconstrói identidades silenciadas promovendo, sobretudo, uma fratura na homogeneidade do cânone literário cabo-verdiano, predominantemente masculino. 


\section{Referências}

Abdalla Júnior, Benjamin. De voos e ilhas: literatura e comunitarismos. São Paulo: Ateliê Editorial, 2003.

Amarílis, Orlanda. Ilhéu dos pássaros. Lisboa: Plátano, 1983.

Amarílis, Orlanda. Thonon-les-ban. In: Amarílis, Orlanda. Ilhéu dos pássaros. Lisboa: Plátano, 1983. p.

AmArílis, Orlanda. A casa dos mastros. Linda-a-velha: ALAC, 1989.

Amarílis, Orlanda. Cais-do-Sodré te Salamansa. Coimbra: Centelha, 1991.

Amarílis, Orlanda. Cais do Sodré. In: Amarílis, Orlanda. Cais-do-Sodré te Salamansa. Coimbra: Centelha, 1991. p. o8-18

Cabral, Ana Maria. Apresentação. In: Duarte, Vera. A Candidata. Belo Horizonte: Nandyala, 2012. p.o6-07

Duarte, Vera. A Candidata. Belo Horizonte: Nandyala, 2012.

Duarte, Vera. Arquipélago da Paixão. Mindelo: Edições Artiletra, 2001.

Duarte, Vera. Amanhã Amadrugada. Praia: Instituto da Biblioteca Nacional e do livro, 2008.

DuArte, Vera. A palavra e os dias. Belo Horizonte: Nandyala, 2013.

Duarte, Vera. Preces e Súplicas ou os Cânticos da Desesperança. Lisboa: Instituto Piaget, 2005 .

Ferreira, Manuel. Literaturas africanas de expressão portuguesa. Lisboa: Biblioteca Breve; Instituto de cultura e língua portuguesa, 1986.

Figueiredo, Jaime (org.). Modernos Poetas Cabo-Verdianos. Praia: Edições Henriquinas; Imprensa Nacional, 1960.

Fonseca, Maria Nazareth Soares; MoreIra Terezinha Taborda. Panorama das literaturas africanas de língua portuguesa. Cadernos Cespuc de Pesquisa. Belo Horizonte, n. 16, p. 13-69, set. 2007. Disponível em: http://periodicos.pucminas.br/ index.php/cadernoscespuc/article/view/14767. Acesso em: 26 out. 2019.

KilombA, Grada. Memórias da plantação: episódios de racismo cotidiano. Rio de Janeiro: Cobogó, 2019.

SAlústio, Dina. A Estrelinha Tlim Tlim. Praia; Mindelo: Centro Cultural Português, 1998.

SAlústio, Dina. A louca de Serrano. Mindelo: Spleen edições, 2012.

SAlústio, Dina. Que os olhos não veem. Praia: Centro Cultural português, 2002. 
SAlÚstio, Dina. Filhas do Vento. Praia: Instituto Nacional do livro, 1999.

SAlústio, Dina. Mornas eram as noites. Praia: INL, 2002.

Salústio, Dina. Filhos de Deus. Praia: Biblioteca Nacional de Cabo Verde, 2018.

SAlústio, Dina. Veromar. Lisboa: Rosa de Porcelana, 2019.

SAlústio, Dina. Não é o escritor que vai à procura da realidade, a realidade é tão forte que nos obriga a escrever. [Entrevista concedida a Cláudia Aranda]. 26 fev. 2018. Ponto Final. Disponível em: https://pontofinalmacau.wordpress.com/2018/ o2/26/nao-e-o-escritor-que-vai-a-procura-da-realidade-a-realidade-e-tao-forteque-nos-obriga-a-escrever/. Acesso em: 26 set. 2019.

SAntilli, Maria Aparecida. As mulheres-sós de Amarílis. In: SAntilli, Maria Aparecida. Africanidade. São Paulo: Ática, 1985. p.

Recebido em 26 de novembro de 2019.

Aprovado em 2 de março de 2020.

\section{Resumo/Abstract/Resumen}

Orlanda Amarílis, Vera Duarte e Dina Salústio: a tessitura da escrita de autoria feminina na ficção cabo-verdiana

\section{Lílian Paula Serra e Deus}

Orlanda Amarílis, Vera Duarte e Dina Salústio: a tessitura da escrita de autoria feminina na ficção cabo-verdiana A escrita de autoria feminina, em especial das escritoras cabo-verdianas Orlanda Amarílis, Dina Salústio e Vera Duarte, contribui para a construção da identidade cabo-verdiana e caminha na direção da contestação da violação de direitos, sobretudo, da mulher. Objetivou-se perscrutar, a partir da tessitura da escrita de autoria feminina, a construção de uma literatura que, ao focar o olhar nas mulheres, para além de, inicialmente, intentar rasurar o ideal colonialista, pautado em uma estrutura patriarcal, expõe, repisa, denuncia, e ressignifica a realidade das mulheres em contextos de opressão. Dessa maneira, a escrita de Amarílis, de Duarte e de Salústio irrompem as fronteiras cabo-verdianas para abarcar "vozes-mulheres" outras que, pelos caminhos da literatura, desconstroem violências estruturais e reconstroem identidades silenciadas.

Palavras-chave: literatura cabo-verdiana, autoria feminina, Orlanda Amarílis, Vera Duarte, Dina Salústio. 


\section{Orlanda Amarílis, Vera Duarte and Dina Salústio: Texture in the Fiction} of Female Cape Verdean Authors

\section{Lílian Paula Serra e Deus}

The writings of women, especially those of the Cape Verdean writers Orlanda Amarílis, Dina Salústio and Vera Duarte, contribute to the construction of the Cape Verdean identity and are aimed at challenging the violation of rights, especially those of women. The objective was to examine, based on the texture of texts written by women, the construction of a literature that, when focusing on women, in addition to initially trying to erase the colonialist ideal, based on a patriarchal structure, exposes, repeats, denounces and re-signifies the reality of women in contexts of oppression. In this way, the writing of Amarilis, Duarte and Salustio erupts on the borders of Cape Verde to embrace "female voices" which, via the pathways of literature, deconstruct structural violence and rebuild silenced identities.

Keywords: Cape Verdian literature, female authorship, Orlanda Amarílis, Vera Duarte, Dina Salústio.

\section{Orlanda Amarílis, Vera Duarte y Dina Salústio: el contexto de la escritura de autoría femenina en la ficción caboverdiana}

\section{Lílian Paula Serra e Deus}

La escritura de autoría femenina, y en especial la de las escritoras caboverdianas Orlanda Amarílis, Dina Salústio y Vera Duarte; contribuye a la construcción de la identidad caboverdiana y camina en la dirección de la contestación de la violación de los derechos, especialmente los de las mujeres. Se pretende examinar, a partir del tejido de la escritura de autoría femenina, la construcción de una literatura que, al centrarse en las mujeres, además de tratar inicialmente de borrar el ideal colonialista, basado en una estructura patriarcal; expone, confronta, denuncia y resignifica la realidad de las mujeres en contextos opresivos. Así, la narrativa de Amarílis, Duarte y Salústio irrumpe en las fronteras de Cabo Verde para abrazar otras "voces-mujeres" que, a través de los caminos de la literatura, deconstruyen violencias estructurales y reconstruyen identidades silenciadas.

Palabras clave: literatura caboverdiana, autoría femenina, Orlanda Amarílis, Vera Duarte, Dina Salústio. 